\title{
Feasibility of using low pressure cold gas spray for the spraying of thick ceramic hydroxyapatite coatings
}

\author{
A.M.Vilardell*, N.Cinca, S.Dosta, I.G.Cano, J.M.Guilemany \\ Centre de Projecció Tèrmica (CPT). Dpt. Ciència dels Materials i Enginyeria Metal.lúrgica. Universitat \\ de Barcelona Martí i Franquès 1, 08028 Barcelona, Spain.
}

*Corresponding author: amvilardell.research@gmail.com

\begin{abstract}
This article deals with the production of thick ceramic hydroxyapatite coatings obtained by Low Pressure Cold Gas Spray (LPCGS) system. Several factors such as powder microstructure, surface roughness and cold gas spray system are here discussed in the build-up process. The use of nanocrystalline powder composed by fine agglomerates and needle-like shape microstructure allows the realignment and compaction of individual crystallites to form thick deposits. In addition, the activation of the substrate surface results convenient for the first impinging particles anchored properly. Then, layer by layer, particles can remain attached leading to coating build-up. Additionally, the use of low shock pressure as well as constant feeding system provided by LPCGS system lead to homogeneous coatings in comparison with High Pressure Cold Gas Spray (HPCGS) system. The successful coating build-up has been achieved not only by the use of an agglomerated feedstock powder, but also by previous surface treatment and the use of the low pressure system.
\end{abstract}

The obtaining of HA components by LPCGS is promising within biomedical field. An improvement of component strength is also suggested by means of thermomechanical analysis of the powder. The performance of a post heat-treatment leads to an increase of HA strength, as well as crystal size.

Keywords: Hydroxyapatite; additive manufacturing; deposition; low pressure cold gas spray;

\section{Introduction}

The Cold Gas Spray (CGS) technology is a solid-state process based on plastic deformation mechanisms of the feedstock material. It was originally intended to be used for the production of dense metallic coatings avoiding any type of transformation and the typical tensile residual stresses found in the as-sprayed coatings obtained by the conventional technologies. CGS has seen a noticeable evolution from the beginning, 
starting by the spraying of ideal metallic materials with relatively low melting point and lower mechanical strength such as $\mathrm{Zn}, \mathrm{Al}$ and $\mathrm{Cu}$, to higher strength materials such as $\mathrm{Fe}, \mathrm{Ni}$, Ti and the corresponding alloys, as well as tantalum and even cermet and ceramic materials [1,2,3].

A careful reading of the few papers published about CGS of ceramics indicates that the actual bonding mechanism is highly dependent on the relative particle-substrate hardness ratio, surface topography and microstructure of the feedstock powder, but the actual mechanism has not been yet well clarified. This would explain why some authors observe the embedment of the ceramic particles into very soft and ductile substrates, whereas others, such as Yamada et al. [4] support a chemical bonding rather than anchoring. It appears that for dense powders, the effective deposition is either possible on soft substrates, where the embedment is possible but the posterior coating build-up is hardly likely [5,6] or, on harder substrates through particle fragmentation [7]. Some attempts have been performed with ceramic powders on soft substrates such as PEEK [8] and magnesium [9]. The first particles impact and embed into the soft substrates; further impinging particles collide on the previous deposited particles and help them to be deeper embedded, mostly resulting in thin layers with posterior coating build-up being hardly likely to occur [2, 10]. On the other hand, it is thought on harder substrates that the optimal particle state for a successful substrate attachment is that in which the Hugoniot Elastic Limit (HEL) of the ceramic is reached [11].

However, recent research has demonstrated the importance of the microstructure of ceramic particles and, as long as they are not dense, the deposition may be feasible, such as in the case of Hydroxyapatite (HA) $[12,13,14]$. Those studies evaluated the deposition of porous sintered microcrystalline HA powders, showing mechanisms proceeding through pore collapse, fragmentation and densification as well as grain refinement. However, the fragmentation of crystal grains which proceed by cracking and crushing, do not lead to the build-up of a coating [12]. On the other hand, the deposition mechanisms of agglomerated nanocrystalline HA powders has been understood by the compaction of nanocrystalline grains within the particle leading to successful build-up of a coating up to $350 \mu \mathrm{m}$ [13].

The present paper goes a step forward presenting the possibility to use the technology to produce thick ceramic coatings, in this case of HA, in contrast to other low temperature processes such as Aerosol Deposition (AD) [15], which are limited to the use of vacuum conditions and submicrometric particles. 


\section{Materials and experimental methods}

Nanocrystalline HA feedstock powder with a particle size distribution between 15-63 $\mu \mathrm{m}$ was obtained from Medicoat (France). The powder has spherical morphology and is composed by fine agglomerates. A laser diffraction (LS) particle size analyzer Beckman Coulter LS 13320 was used to study the granulometry of the feedstock powders. Therefore, real density was evaluated with the same protocol that in previous research [13].

The microstructural characterization of the powder was carried out by Transmission Electron Microscopy (TEM) using a JEM 2100 microscope, operated at $200 \mathrm{kV}$ (with current density of $80-250 \mathrm{pA} / \mathrm{cm}^{2}$ ). The XRay Diffraction (XRD) measurements were carried out on a Bragg-Brentano $\theta / 2 \theta$ Siemens D-500 diffractometer with $\mathrm{Cu} \mathrm{K \alpha}$ radiation. The phase identification was analyzed with X'Pert PRO MPD diffractometer (PANalytical).

Ti6Al4V coupons were used as substrates and three different surface treatments were evaluated to study the influence of coating build-up, i.e. by (i) grinding with \#240 SiC paper, (ii) sandblasting (SB) with alumina particles grit 24 , and the deposition of highly rough CP-Ti coating [16]. Two CGS systems were used for the HA deposition: (i) Low Pressure Cold Gas Spray (LPCGS) Dycomet 423 equipment (The Netherlands) and (ii) High Pressure Cold Gas Spray (HPCGS) KINETICS®4000 (Ampfing, Germany). The LPCGS is limited to the use of air as the propellant gas and works with a maximum operating pressure of 10 bars and temperature of $600{ }^{\circ} \mathrm{C}$; the HPCGS has a maximum operating pressure of 40 bars, temperature of $800{ }^{\circ} \mathrm{C}$ and operates with nitrogen as the propellant gas. The cross-section of the coatings were subjected to metallographic procedure by grinding up to $4000 \mathrm{SiC}$ paper and then polishing with colloidal silica.

In order to strengthen HA bulk deposits, a thermomechanical analysis of the HA feedstock powder was performed to analyze the phase transitions and chemical reactions. The equipment used for that purpose was a Setaram TMA Setsys $16 / 18$ (France). The temperature range is from $25^{\circ} \mathrm{C}$ up to $1600{ }^{\circ} \mathrm{C}$ with an accuracy of $0.01 \mu \mathrm{m}$, using a heat rate of $5^{\circ} \mathrm{C} / \mathrm{min}$. Thus, two Thermal Treatments (TT) were performed, at $1000{ }^{\circ} \mathrm{C}$ and $1400{ }^{\circ} \mathrm{C}$ under controlled atmosphere with Argon. Therefore, free surface area of the specimens was examined by Field Emission Scanning Electron Microscopy (FESEM), using a JEOL JSM 7100F equipment. 


\section{Results}

\subsection{Powder microstructure}

The HA powder that has been used for the present study exhibits spherical morphology and, at high magnification, the microstructure is observed to be an agglomeration of fine particulates. Rather than keeping the strength of a sintered ceramic, the single particles, with a real density of $0.485 \mathrm{~g} / \mathrm{cm}^{3}$, showed a tendency to loose easily the as-provided round shape [13]. Figure 1a shows the particle size distribution of the as-received powder in which both, differential (continuous line) and accumulative (dashed line) volume percentages are plotted. As it can be observed, the particles show a broad distribution where the $\emptyset_{\text {mean }}=33.0 \mu \mathrm{m}$, being the $\emptyset_{10}=22.7 \mu \mathrm{m}$ and $\emptyset_{90}=56.4 \mu \mathrm{m}$. A tail of fine particles below to $15 \mu \mathrm{m}$ and a coarse tail of coarse particles from $80 \mu \mathrm{m}$ to $140 \mu \mathrm{m}$ can be observed. Figure $1 \mathrm{~b}$ shows the differential number percentage of particles versus particle diameter percentage according to the number percentage of the particles. It can be clearly observed that there is a high amount of particles under $1 \mu \mathrm{m}$ particle size.

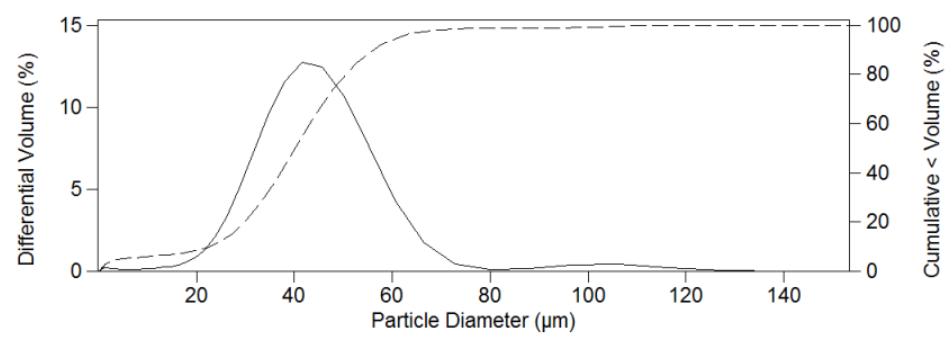

a)

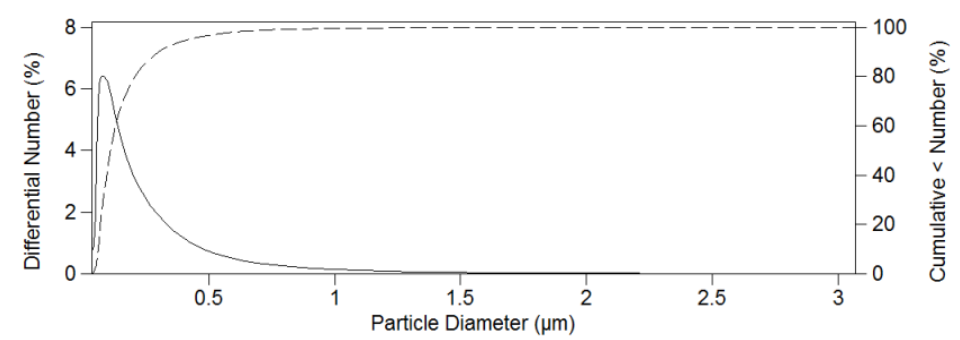

b)

Figure 1. Particle size distribution of the as-received sintered HA powder a) differential volume and b) differential number percentages as $Y$ axis versus particle diameter as $X$ axis.

Figure 2 shows the needle-like shape featured microstructure of HA powder (Fig. 2). The electron diffraction (inset fig. 2) showed a ring pattern indicating the presence of the small crystallite sizes, which had as well been confirmed previously by XRD [13]. 


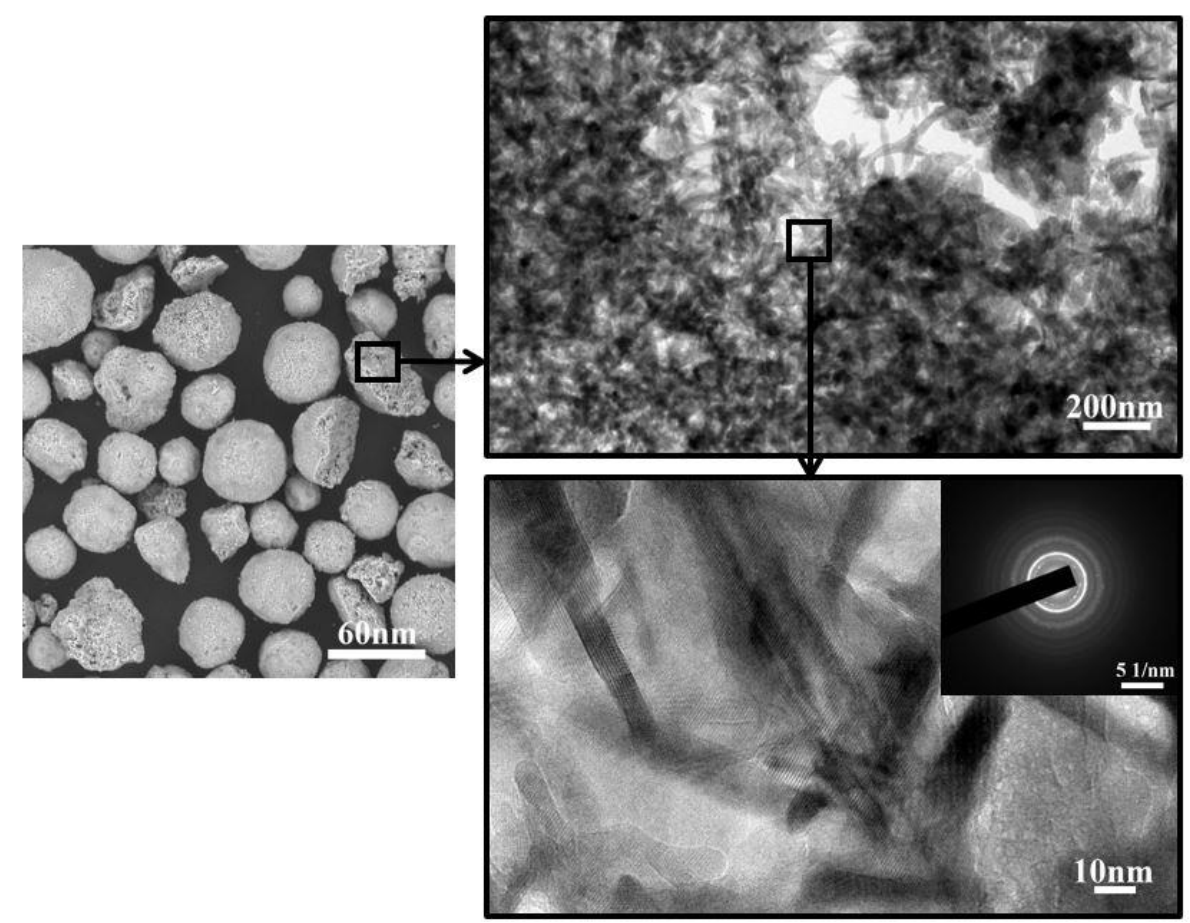

Figure 2. SEM and TEM micrographs of HA feedstock powder and its microstructure.

\subsection{Surface activation and CGS systems}

Direct deposition onto a Ti6Al4V alloy coupon did not provide suitable deposition and coating build-up.

The low density of certain ceramics causes the blow of the small particles through the high impact gas jet (Fig. 3, left), usually known as bow shock effect [17]. Therefore, just few of HA particles were able to deposit onto the substrate. In order to increase the deposition efficiency and achieve an initial improved particle bonding, the activation of the surface was attempted by spraying onto three different types of surface roughness's: (i) grinding with \#240 $\mathrm{SiC}$ paper, and (ii) sandblasting (SB) with alumina particles the Ti6Al4V alloy substrate, as well as by the deposition of a highly rough CGS CP-Ti coating [16] (Fig. 3, right).

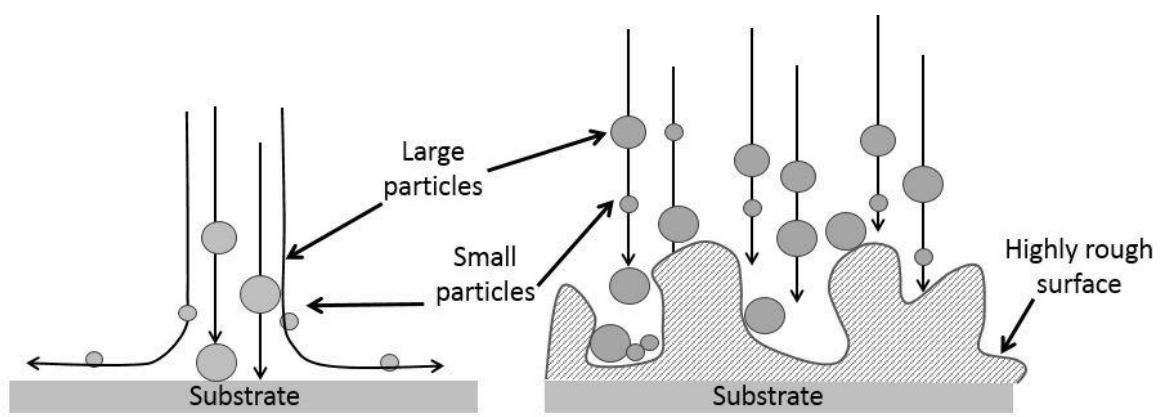

Figure 3. Particle trajectories of low dense ceramic particles by CGS. 


\subsection{High and low pressure CGS systems}

Figure 4 shows the optimized CGS conditions of HA powder [18] onto the three substrates with HPCGS (Fig. 4a) and LPCGS (Fig. 4b) systems. The low rough surfaces obtained after ground or sandblasted treatments did not contribute enough on the activation of the surfaces in comparison with the high rough CGS CP-Ti coating. Initial attempts on using HPCGS were not successful at all, showing thick but highly inhomogeneous coatings, due to the design of the feeding system (Fig. 4a). Therefore, the constant feeding system of LPCGS and the assumption that not much large shock pressures seems to be more suitable for this particular structure of the feedstock (Fig. 4b). The results obtained with the low pressure system were incredibly successful, with highly homogeneous deposits; by using as well the appropriate combination of spraying parameters such as traverse gun speed, feeding rate, gas pressure and temperature, cohesive and well-adhered thick coatings were obtained [18].

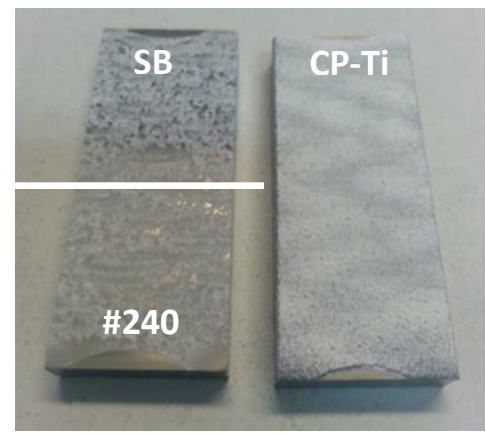

a)

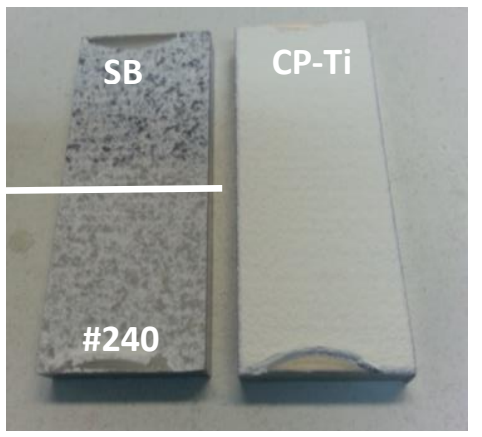

b)

Figure 4. Agglomerate HA powder deposited onto SB and \#240 SiC grinded Ti6Al4V alloy coupon surfaces and onto highly- rough CGS CP-Ti coating by a) HPCGS and b) LPCGS.

The cross section area of HA onto CGS CP-Ti bondcoat by LPCGS is shown in figure 5 . The first impinging HA particles impact onto the high surface and anchor properly by filling up the valleys of the surface roughness, thus leading to the build-up of the coating.
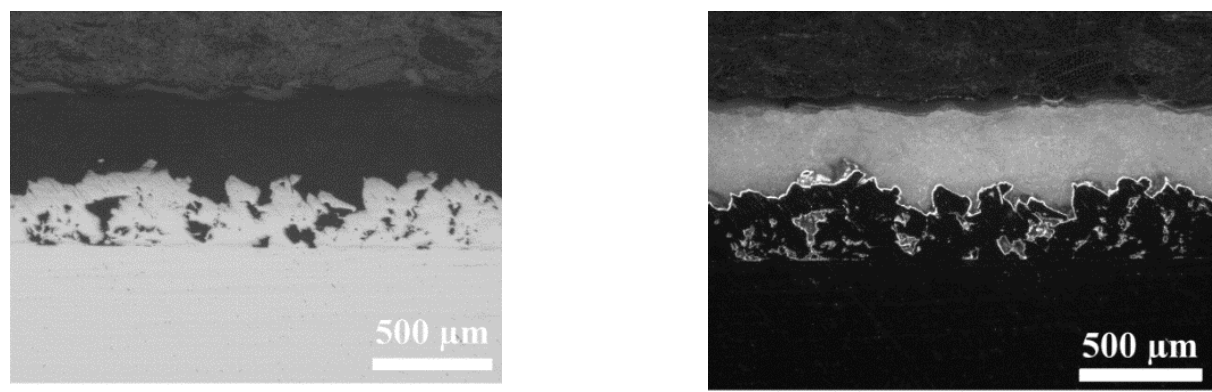
Figure 5. Optical micrographs of HA coating obtained by LPCGS, a) Bright field and b) Dark field. Figure 6a shows the evolution of the progressive build-up of the coating from 1 to 4 layers as well as their thickness values (Fig. 6b) with the optimal spraying conditions [18]. In addition, the nanocrystalline structure is well maintained since the XRD of the feedstock powder and the coating are analogous [13]. The preservation of the fine structure, as observed revealed in previous studies by XRD, is interesting in terms of keeping a similar bone microstructure. A final thickness of $10 \mathrm{~mm}$ was obtained after 10 passes.

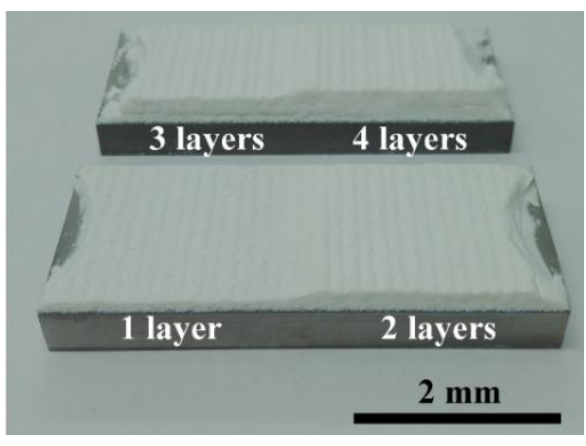

a)

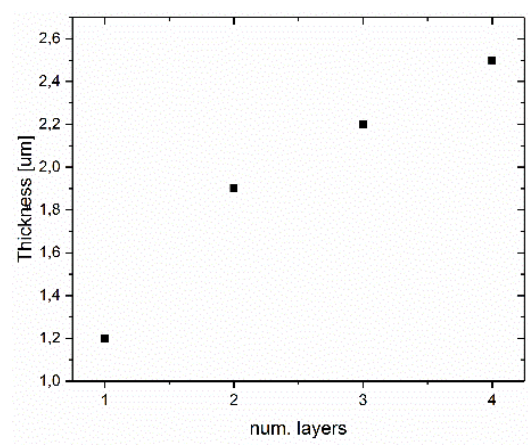

b)

Figure 6. a) Macrograph image and b) thickness of LPCGS HA coatings after 1, 2, 3 and 4 layers.

\subsection{Thermal treatments of HA bulks}

The formation of thin layers is desirable for bioactive coatings in cementless orthopedic applications. However, the production of thick coatings to be considered as bulks needs that they can be detached afterwards; further thermal treatments can be performed with the aim to increase their structural strength in case that it may be used for bone graft. The as-sprayed coatings seem to behave as a ceramic green preform before sintering the material. As it has been exposed for other materials, the spraying process promotes compaction but not the required densification so that the piece is as consistent as the bulk hydroxyapatite [19].

First attempts to develop a thermal treatment were performed according to the thermomechanical analysis of HA powder (Fig. 7). Thus, according to the dilatometry graph, two different thermal treatments were performed with the aim to know the most suitable temperature so that it becomes densified. The first one consists in increasing the temperature up to $1000{ }^{\circ} \mathrm{C}$ at $5^{\circ} \mathrm{C} / \mathrm{min}$, while the second thermal treatment up to $1400^{\circ} \mathrm{C}$. Inset micrographs of figure 7 show the top surfaces of as-sprayed HA bulk, and after both thermal treatments. The increase of sub-micron HA grains of HA particles increases with the increase of the 
temperature of the thermal treatment. Therefore, both thermal treatments lead to crystalline phase structure (Fig. 8).

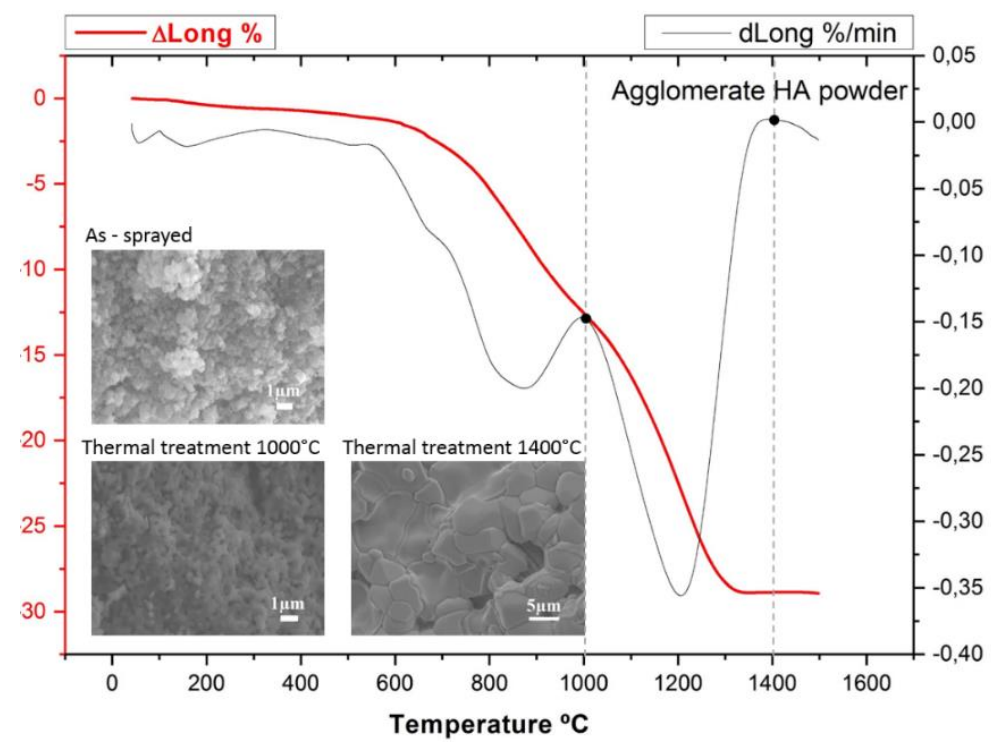

Figure 7. Dilatometry and FESEM micrographs of the top surface of HA bulks: as-sprayed and after thermal treatments at 1000 and $1400{ }^{\circ} \mathrm{C}$.

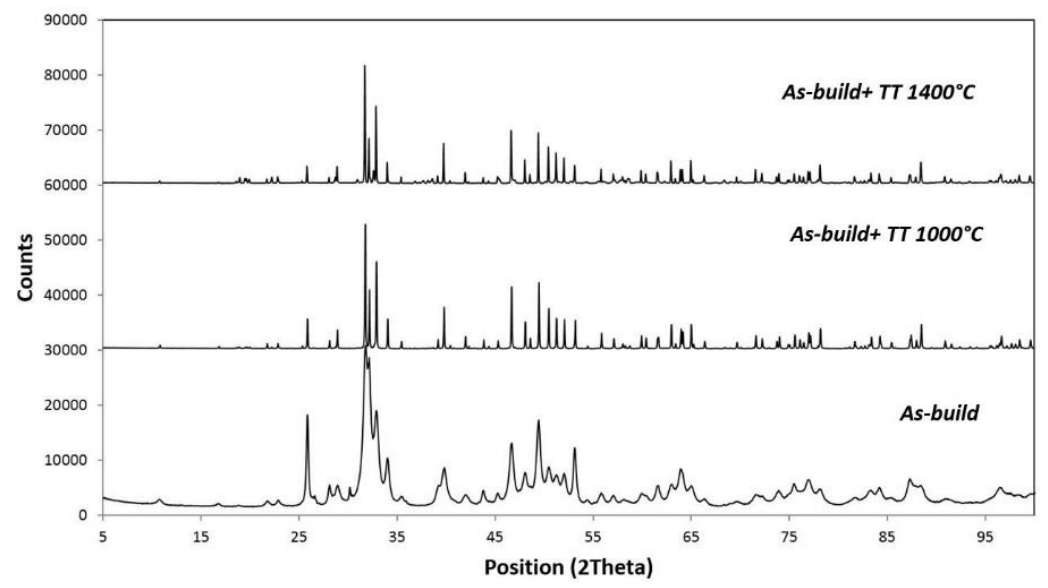

Figure 8. XRDs of HA bulks: as-sprayed and after TT at $1000{ }^{\circ} \mathrm{C}$ and $1400{ }^{\circ} \mathrm{C}$.

\section{Discussion}

\subsection{Build-up of ceramic HA coating}

Without the thermal input of the conventional spraying technologies, we avoid the decomposition of the HA phase into other phases whose solubility in the body fluids cannot be much controlled [20]. The use of 
the CGS technique can overcome this handicap but the feedstock may lack of toughness to be able to produce a suitable coating. The use of a HA feedstock has overcome such handicap but another key point has been proved to be necessary to build-up a coating with noticeable thickness, this is the surface activation by considerable roughening. The valleys on the surface could thus be filled and serve as further contact points for proper build-up. In addition, the LPCGS system was observed to be more suitable than the HPCGS by means of feeding rates. The LPCGS was originally created as a portable system for industrial environment. Two fundamental aspects that distinguish LPCGS from HPCGS are: (i) The utilization of low pressure gas (0.5-1 MPa instead of 2.5-3 MPa) and (ii) Radial injection of the powder instead of axial injection (in most cases) [21]. In LPCGS process, feedstock particles are drawn in from the powder feeder by Venturi effect, contrary of the particles in HPCGS, which are mixed with the propellant gas in the prechamber zone and then are axially fed into the gas stream [22]. Due to that, LPCGS system was observed to be more suitable than the high pressure, due to the more constant feeding rate.

In addition, the need of surface activation has been sometimes reported to be beneficial for coating deposition [23,24], reducing the induction time required for bonding, although controversy also arises when this implies surface hardening that makes difficult simultaneous particle-substrate deformation. However, as it has been here proved, it seems to play some role regarding ceramic materials with small particle size and low density, although more related to compaction and constraint of particles deposited within the valleys of the roughened surface [25].

Once the valleys are full, the build-up process appears to be a result of a compaction mechanism of the deposited ceramic particles [19]; we previously reported that this may be attributed to the tamping effect produced by continuous impact of incoming particles onto the already adhered ones. Particle contours are not more distinguishable and the original filaments of the agglomerates become compacted (Fig.9). This has also been observed in other room temperature techniques, such as: Vacuum Cold Gas Spraying (VCGS) [26], AD [27] or Nano Particle Deposition System (NPDS) [28] for different ceramic powders, but they mainly use sub-micron sized particles, the spraying system is slightly different and there is not need of surface activation. In such processes, the suggested mechanism for ceramic deposition is described in two steps: the fragmentation of submicron ceramic particles into nanoparticles and the successive impact of submicron particles, which provides sufficient bonding energy in the form of heat and pressure to the fragmented nanoparticles via the shock wave. Dense HA coatings up to $1 \mu \mathrm{m}$ have been obtained onto titanium alloy substrates by $\mathrm{AD}$ technique for coatings implant. However, the same study reported a HA 
thickness up to $100 \mu \mathrm{m}$ [29]. Therefore, dense ceramic layers of $\alpha-\mathrm{Al}_{2} \mathrm{O}_{3}$ and PZT with thickness of $1-100$ $\mu \mathrm{m}$ were successfully formed on glass, plastic, and metal substrates with agglomerate and submicronic feedstock powder by the same technique [27]. $\mathrm{TiO}_{2}$ particles of a size of $25 \mathrm{~nm}$ and $200 \mathrm{~nm}$ were successfully deposited by VCGS on conducting glass and stainless steel substrates. Apparently, dense coatings consist of particles stacked as agglomerates that build-up together with the number of spray passes. In comparison with CGS, the specimen in VCGS is placed in a vacuum tank coupled to a vacuum pump with a pressure that is substantially less than the atmospheric pressure. The vacuum tank allows for gas recovery and for powder overspray collection. These authors achieved a coating thickness of $\sim 40 \mu \mathrm{m}$ with 12 passes with a $25 \mathrm{~nm}$ particle size [26].

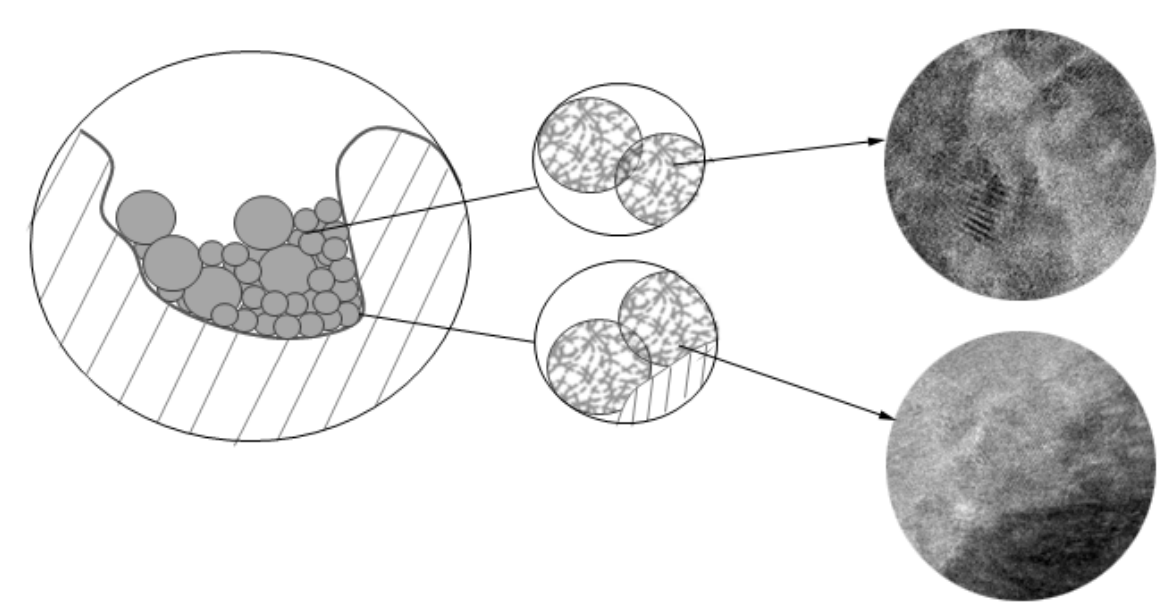

Figure 9. Deposition of agglomerate HA particles onto a valley of a rough surface.

Rather than VCGS, the use of micron sized ceramic particles but with nanoagglomerate structure is highly advantageous in CGS compared to others such as sintered powders since the impact energy may be directly used for compaction rather than neck fracture and grain crushing. As previously reported, $\mathrm{E}_{\mathrm{kinetic}}=\mathrm{E}_{\mathrm{fracture}}+$ $E_{\text {thermal }}[12]$, but here the energy necessary to fracture the agglomerated particles is much lower than the corresponding for a sintered particle. This is why, in the present study, coatings up to $\sim 5 \mathrm{~mm}$ thick after 10 passes can be reached without delamination.

\subsection{Improving component strength}

The production of thick coatings was surprising but further thermal treatments should be performed with the aim to increase their structural strength so that they can have consistency in the application. For that purpose, heating is needed to activate diffusion mechanisms. The grain boundary diffusion and lattice diffusion from the grain boundary to the neck are the most important densifying mechanism in 
polycrystalline ceramics. Diffusion from the grain boundaries to the pores permits neck growth as well as shrinkage (densification) [30]. After the thermal treatment at $1000^{\circ} \mathrm{C}$, submicron grains start coalesce and reduce pore size. At a thermal treatment at $1400^{\circ} \mathrm{C}$, sinterization occurs and it is observed a dense structure with big grains between 5-10 $\mu \mathrm{m}$. The XRDs from HA bulks of both thermal treatments show narrower pecks than XRD from the as-sprayed HA bulk, indicating the grown up of crystal size from nanocrystalline to crystalline within the HA bulk.

Pure crystalline HA powders used to shown one peak between the range of $1000{ }^{\circ} \mathrm{C}$ and $1200{ }^{\circ} \mathrm{C}$ on dilatometry graphs. This temperature is associated to the sinterization temperature and phase transformations take place [31]. The presence of a second peak in the present case of HA powder, could appear as the presence of other elements [32] or amorphous phase [33]. As reported in previous research [13], HA coating has a content of $86.58 \%$ HA, $2.07 \%$ of monetite phase and $11.34 \%$ of amorphous phase, which mostly consists of a dehydroxylated calcium phosphate. When heated, the crystallization of hydroxyl-rich areas produces HA, followed by diffusion of hydroxyl ions, thus increasing the amount of crystalline phase. Hydroxyl-deficient amorphous areas crystallize to oxyapatite at $700{ }^{\circ} \mathrm{C}[33]$.

Bone grafts proved to be successful in humans and animals, especially orthopedic cases like intrabone defect repairs, maxillofacial surgery, jaw bone restoration and augmenting mandibular ridge. It eliminates the need for patients to undergo painful autograft bone grafting procedures [34]. B-OstIN is made by wet chemical methods and thereafter converted into porous mass (60-70\% porosity with pores size between $100-300 \mu \mathrm{m})$ through ceramic processing routes. B-OstIN is most osteoconductive material which helps in bone bonding within 3 months [35]. Some bone grafts used to be composed by mineral-collagen composite matrix in order to enhance biological response. Ossigen ${ }^{\circledR}$ has mineral particles dispersed within collagen fibers forming a three-dimensional porous matrix consist of $80 \%$ bone mineral and $20 \%$ collagen by dry weight with a 100-400 $\mu \mathrm{m}$ optimal pore size for tissue regeneration [36]. Those commercial grafts are commercialized by blocks. HA bulks by CGS could be a good and economic process to build-up customized grafts with the desired composition, shape and microstructure. However, more studies should be performed for future perspectives.

\section{Conclusion}

Thick ceramic HA coatings were successfully obtained by LPCGS. Several factors such as powder microstructure, surface roughness and CGS system are involved in the build-up process. 
- Nanocyrstalline mictrostructured HA powder with needle-like shape morphology resulted on the compaction of nanocrystals, thus leading to the build-up of the coating.

- The activation of the substrate surface is convenient for the first impinging particles to anchor properly to build-up the coating. A highly rough surface is required in for that purpose.

- The feeding rate of LPCGS system leads to more constant feeding rates in comparison with HPCGS.

\section{Acknowledgments}

The authors want to thank the Spanish MINECO for financial support through project MAT2016-46755R, the Generalitat de Catalunya for the project 2017 SGR 1777, and University of Barcelona for the award of a scholarship that has helped the development of this research.

\section{References}

[1] Schmidt T, Gärtner F, Assadi H, Kreye H. Development of a generalized parameter window for cold spray deposition. Acta Mater. 2006;54(3):729-42.

[2] Dosta S, Couto M, Guilemany JM. Cold spray deposition of a WC-25Co cermet onto Al7075-T6 and carbon steel substrates. Acta Mater. 2013;61(2):643-52.

[3] Vilardell AM, Cinca N, Concustell A, Dosta S, Cano IG, Guilemany JM. Cold spray as an emerging technology for biocompatible and antibacterial coatings: state of art. J Mater Sci. 2015;50(13):4441-62.

[4 ] Yamada M, Isago H, Shima K, Nakano H, Fukumoto M. Deposition of TiO2 Ceramic Particles on Cold Spray Process; Paper presented at: Proceedings of Thermal Spray 2010: Global Solutions for Future Applications, Springer-Verlag, New York, NY, 2011. pp. 172-6

[5] Seo D, Sayar M, Ogawa K. SiO2 and MoSi2 formation on Inconel 625 surface via SiC coating deposited by cold spray. Surf Coat Tech. 2012;206(11-12):2851-8.

[6] Kliemann J-O, Gutzmann H, Gärtner F, Hübner H, Borchers C, Klassen T. Formation of Cold-Sprayed Ceramic Titanium Dioxide Layers on Metal Surfaces. J Therm Spray Techn. 2011;20(1-2):292-8. 
[7] Park H, Cao F, Kwon J, Lee C. The Effect of Schock-Induced Plastic Deformation on Alumina Deposition During Vacuum Kinetic Spraying; Paper presented at: Proceedings of Thermal Spray 2013: Innovative Coating Solutions for the Global Economy, ASM International, Novelty, OH, 2014. pp. 27985.

[8] Lee JH, Jang HL, Lee KM, Baek H-R, Jin K, Hong KS, et al. In vitro and in vivo evaluation of the bioactivity of hydroxyapatite-coated polyetheretherketone biocomposites created by cold spray technology. Acta Biomater. 2013;9(4):6177-87.

[9] Noorakma ACW, Zuhailawati H, Aishvarya V, Dhindaw BK. Hydroxyapatite-Coated MagnesiumBased Biodegradable Alloy: Cold Spray Deposition and Simulated Body Fluid Studies. J Mater Eng Perform. 2013 Oct;22(10):2997-3004.

[10] Kergourlay E, Grossin D, Cinca N, Josse C, Dosta S, Bertrand G, et al. First Cold Spraying of Carbonated Biomimetic Nanocrystalline Apatite on Ti6Al4V: Physical-Chemical, Microstructural, and Preliminary Mechanical Characterizations: First Cold Spraying of Carbonated Biomimetic Nanocrystalline. Adv Eng Mater. 2016;18(4):496-500.

[11] Park H, et al., The Effect of Schock-Induced Plastic Deformation on Alumina Deposition During Vacuum Kinetic Spraying; ed., ASM International, Novelty, OH, 2014.

[12]Cinca N, Vilardell AM, Dosta S, Concustell A, Garcia Cano I, Guilemany JM, et al. A New Alternative for Obtaining Nanocrystalline Bioactive Coatings: Study of Hydroxyapatite Deposition Mechanisms by Cold Gas Spraying. Bandyopadhyay A, editor. J Am Ceram Soc. 2016;99(4):1420-8.

[13] Vilardell AM, Cinca N, Cano IG, Concustell A, Dosta S, Guilemany JM, et al. Dense nanostructured calcium phosphate coating on titanium by cold spray. J Eur Ceram Soc. 2017;37(4):1747-55.

[14] Moos R. An Overview of the Aerosol Deposition Method: Process Fundamentals and New Trends in Materials Applications. 2015 [cited 2018 Mar 23];(03). Available from: http://www.ceramicscience.com/journal/article.php?doi=10.4416/JCST2015-00018

[15] Akedo J, Lebedev M. Piezoelectric properties and poling effect of $\mathrm{Pb}(\mathrm{Zr}, \mathrm{Ti}) \mathrm{O} 3$ thick films prepared for microactuators by aerosol deposition. ApplPhys Lett. 2000 Sep 11;77(11):1710-2. 
[16] Vilardell AM, Cinca N, Pacheco I, Santiveri C, Dosta S, Cano IG, et al. Hierarchical structures of anodised cold gas sprayed titanium coatings. Transactions of the IMF. 2018 Mar 4;96(2):71-8.

[17] Samareh B, Dolatabadi A. Dense Particulate Flow in a Cold Gas Dynamic Spray System. J Fluids Eng. 2008;130(8):081702.

[18] Vilardell AM, Cinca N, Dosta S, Cano IG, Guilemany JM, 2016 Mulifuctionalmiro-nano structured hydroxyapatite Coatings on titanium Ti6Al4V for biomedical Applications by Cold Gas Spray, Núm. de solicitud: 809 País de prioridad: ESPA־NA Entidad Titular: UBAR - Universitat de Barcelona.Depósito Legal: 17/04/2015 Trade\& Industrial Secret Number 809 submitted for the Thermal Spray Centre (University of Barcelona) on 17 April 2015 to the Spanish iPP protection.

[19] Gardon M, Fernández-Rodríguez C, Garzón Sousa D, Doña-Rodríguez JM, Dosta S, Cano IG, et al. Photocatalytic Activity of Nanostructured Anatase Coatings Obtained by Cold Gas Spray. J Therm Spray Techn. 2014t;23(7):1135-41.

[20] Moridi A, Hassani-Gangaraj SM, Guagliano M, Dao M. Cold spray coating: review of material systems and future perspectives. Surf Eng. 2014;30(6):369-95.

[21] Champagne VK, editor. The cold spray materials deposition process: fundamentals and applications. Cambridge: Woodhead; 2007. 362 p.

[22] Singh H, Sidhy TS, Kalsi SBS, Cold spray technology: future of coating deposition processes, Frattura Ed Integr Strutt. 2012:22:69-84.

[23] Makinen H, Langeborn J, Vuoristo P. Adhesion of Cold Sprayed coatings: effect of powder, substrate and heat treatment. Paper presented at: Proceedings of the 2007 International Thermal Spray Conference Global Coating Solutions, May 14-16, 2007, Beijing, China pp. 31-36.

[24] Sakaki K, Tajima T, Li H, Shinkai S, Shimitzu Y. Influence of substrate conditions and traverse speed on cold sprayed coatings. Paper presented at: International Thermal Spray Conference 2004: Advances in Technology and Application, Osaka (Japan), ASM International, pp.358-362.

[25] Akedo J. Room Temperature Impact Consolidation (RTIC) of Fine Ceramic Powder by Aerosol Deposition Method and Applications to Microdevices. J Therm Spray Techn. 2008;17(2):181-98. 
[26] Fan S-Q, Yang G-J, Li C-J, Liu G-J, Li C-X, Zhang L-Z. Characterization of Microstructure of NanoTiO2 Coating Deposited by Vacuum Cold Spraying. J Therm Spray Techn. 2006 1;15(4):513-7.

[27] Akedo J. Aerosol Deposition of Ceramic Thick Films at Room Temperature: Densification Mechanism of Ceramic Layers. Journal of the American Ceramic Society. 2006 Jun;89(6):1834-9.

[28] Kim M-S, Chun D-M, Choi J-O, Lee J-C, Kim K-S, Kim YH, et al. Room temperature deposition of TiO2 using nano particle deposition system (NPDS): Application to dye-sensitized solar cell (DSSC). I J Precis Eng Manuf. 2011;12(4):749-52.

[29] Hahn B-D, Park D-S, Choi J-J, Ryu J, Yoon W-H, Kim K-H, et al. Dense Nanostructured Hydroxyapatite Coating on Titanium by Aerosol Deposition. J Am Ceram Soc. 2009;92(3):683-7.

[30] Sōmiya S, editor. Handbook of advanced ceramics: materials, applications, processing, and properties. Second edition. Amsterdam ; Boston: Academic Press, imprint of Alsevier; 2013. 1229 p.

[31] Landi E, Tampieri A, Celotti G, Sprio S. Densification behaviour and mechanisms of synthetic hydroxyapatites. J Eur Ceram Soc. 2000;20(14-15):2377-87.

[32] Cacciotti I, Bianco A, Lombardi M, Montanaro L. Mg-substituted hydroxyapatite nanopowders: Synthesis, thermal stability and sintering behaviour. J Eur Ceram Soc. 2009;29(14):2969-78.

[33] Gross KA, Gross V, Berndt CC. Thermal Analysis of Amorphous Phases in Hydroxyapatite Coatings. J Am Ceram Soc. 2005;81(1):106-12.

[34] Biocollagen technologies: http://www.bio-coll.com/products.php?action=more\&id=4 Accessed: 06 July 2016.

[35] Basic-healthcare healthy foundation: http://www.b-ostin.com/basic-healthcare-biomaterials.htm Accessed: 06 July 2016.

[36] ExacTECH company: https://www.exac.com/products/biologics/ossigen-collagen-composite Accessed: 06 July 2016. 